\title{
UCERF3: A New Earthquake Forecast for California's Complex Fault System
}

$W$ model for California, a region under constant threat from potentially damaging events. The new model, referred to as the third Uniform California Earthquake Rupture Forecast, or "UCERF3" (http://www.WGCEP.org/ UCERF3), provides authoritative estimates of the magnitude, location, and likelihood of earthquake fault rupture throughout the state. Overall the results confirm previous findings, but with some significant changes because of model improvements. For example, compared to the previous forecast (UCERF2), the likelihood of moderate-sized earthquakes (magnitude 6.5 to 7.5 ) is lower, whereas that of larger events is higher. This is because of the inclusion of multifault ruptures, where earthquakes are no longer confined to separate, individual faults, but can occasionally rupture multiple faults simultaneously. The public-safety implications of this and other model improvements depend on several factors, including site location and type of structure (for example, family dwelling compared to a long-span bridge). Building codes, earthquake insurance products, emergency plans, and other risk-mitigation efforts will be updated accordingly. This model also serves as a reminder that damaging earthquakes are inevitable for California. Fortunately, there are many simple steps residents can take to protect lives and property.

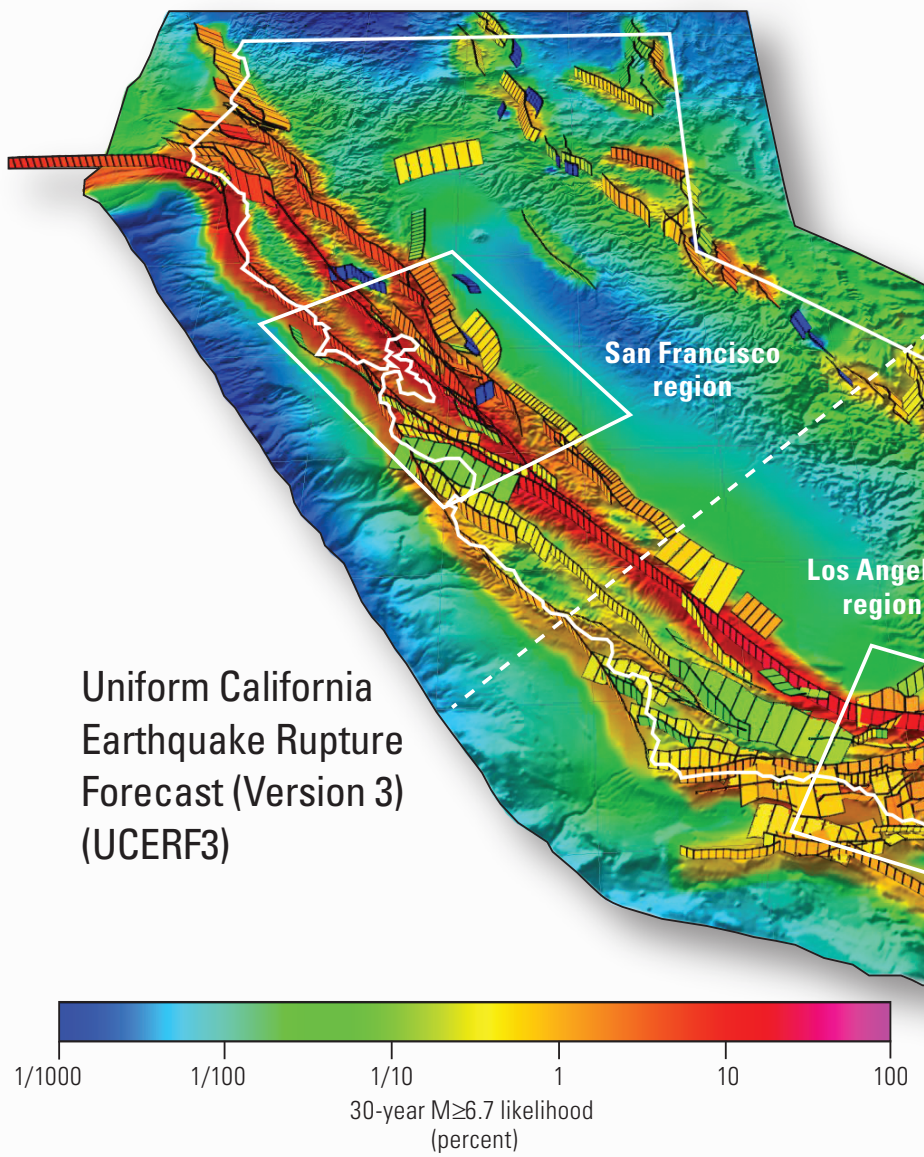

\section{What is UCERF3?}

California is sandwiched between the Pacific and North American tectonic plates, with the former migrating northwest about two inches per year compared to the latter. The plate boundary is far from smooth, reflecting more of a fragmented zone locked in a tectonic battle over which areas will give way, producing some of the steepest mountain ranges in the world. The sliding between plates is also not steady, but rather plays out in fits and starts with periods of rest interrupted by sudden slip along cracks in the Earth. These "fault ruptures" in turn cause the ground to shake, much like the ripples that radiate from a pebble tossed in a pond, and it is this shaking that causes the most damage in earthquakes.

Two kinds of scientific models are used to help safeguard against earthquake losses: an Earthquake Rupture Forecast, which tells us where and when the Earth might slip along the state's many faults, and a Ground Motion Prediction model, which estimates the subsequent shaking given one of the fault ruptures. UCERF3 is the first type of model, representing the latest earthquake-rupture forecast for California. It was developed and reviewed by dozens of leading scientific experts from the fields of seismology, geology, geodesy, paleoseismology, earthquake physics, and earthquake engineering. As such, it represents the best available science with respect to authoritative estimates of the magnitude, location, and likelihood of potentially damaging earthquakes throughout the state (further background on these models, especially with respect to ingredients, can be found in U.S. Geological Survey Fact Sheet 2008-3027, http://pubs.usgs.gov/fs/2008/3027/).

Figure 1. Three-dimensional perspective view of the likelihood that each region of California will experience a magnitude 6.7 or larger $(\mathrm{M} \geq 6.7)$ earthquake in the next 30 years $(6.7$ matches the magnitude of the 1994 Northridge earthquake, and 30 years is the typical duration of a homeowner mortgage).

Faults are shown by the rectangles outlined in black. The entire colored area represents greater California, and the white line across the middle defines northern versus southern California. Results do not include earthquakes on the Cascadia Subduction Zone, a 750-mile offshore fault that extends about 150 miles into California from Oregon and Washington to the north. 


\section{Fault Model Evolution}
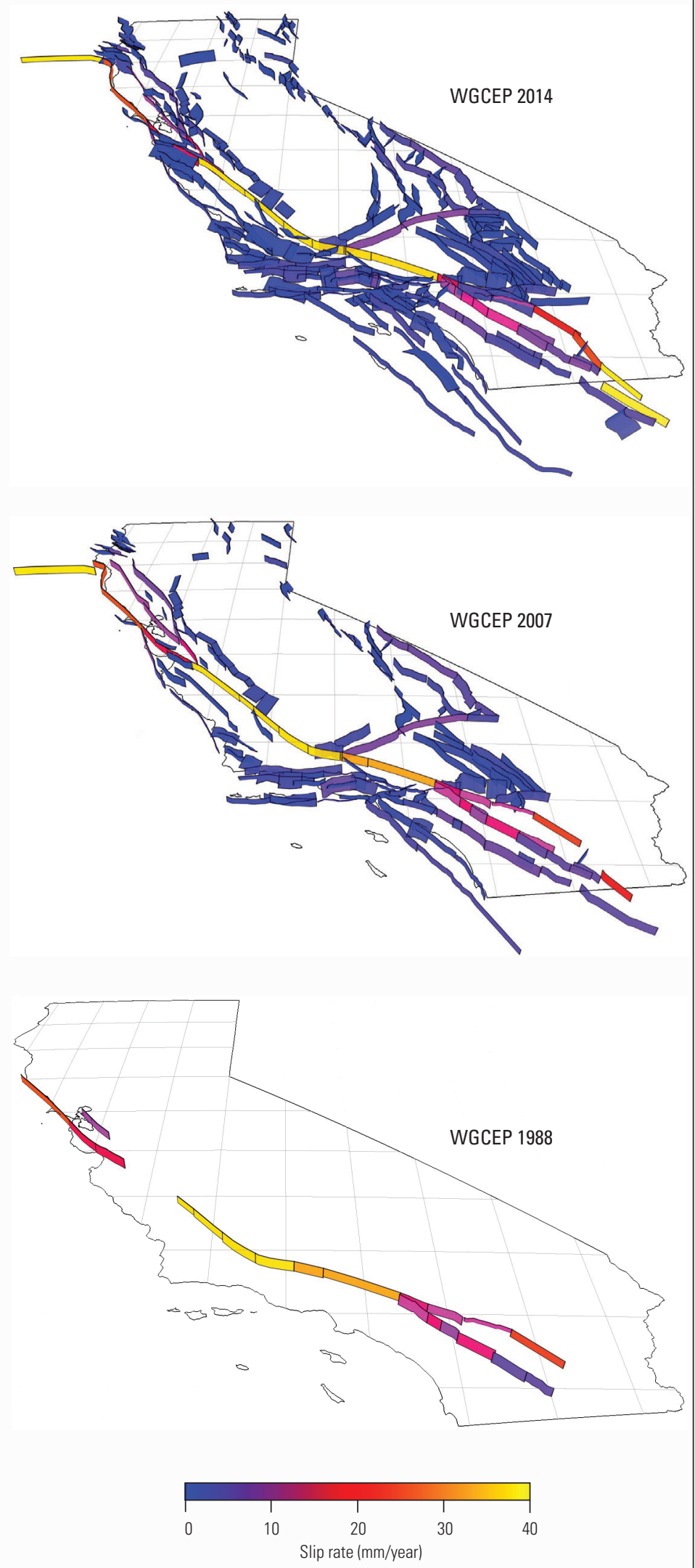

Figure 2. Changes with time of the inventory of faults used in California earthquake forecast models (WGCEP, Working Group on California Earthquake Probabilities).

\section{Why a New Earthquake Forecast Model?}

All scientific models, including earthquake rupture forecasts, are an approximation of the physical system they represent, in the same way that "the map is not the actual territory" (Korzbski, 1931). UCERF3 represents the latest model from the Working Group on California Earthquake Probabilities (WGCEP) (WGCEP, 2014), which also released forecasts in 1988, 1990, 1995, 2003, and 2007. This historical progression of models reflects increasingly accurate, detailed, and sophisticated representations of a particularly complex natural system.

A puzzling feature of previous models has been a forecasted rate of moderate-sized earthquakes (between magnitude 6.5 and 7.0) that is up to a factor of two higher than that observed historically. The first discovery of this discrepancy, by the 1995 WGCEP, was particularly disturbing in that one such event, the magnitude 6.71994 Northridge earthquake, had just surprised many as the costliest earthquake in U.S. history. In fact, the prospect of such events becoming more frequent contributed to an ensuing homeowner-insurance-availability crisis, as most insurance providers opted to pull out of the market altogether, rather than comply with a state law requiring they offer an earthquake option with each policy. This insurance availability crisis was ultimately solved in 1996 with the legislative creation of the California Earthquake Authority (http://www.earthquakeauthority.com), which has since become the largest earthquake insurance provider in the state. However, the discrepancy between the forecast rate and the observed rate at moderate magnitudes has remained through the most recent previous study (WGCEP, 2007), and scientists have hotly debated whether this is real or a result of some model limitation.

Recent earthquakes have fortunately provided clues. For example, the Northridge earthquake occurred on a previously unrecognized fault, which motivated scientists to search for other faults and quantify those that might be capable of producing damaging earthquakes. The effort has paid off. Whereas the 1988 WGCEP considered only 16 different faults, albeit the main ones, by the time of the WGCEP 2007 effort there were about 200. With UCERF3, there are now more than 350 fault sections in the model, thanks in part to using space-based geodesy where geologic data are limited. This historical progression is shown in the fault model evolution figure at left.

Another clue with respect to the moderate-magnitude rate discrepancy is that many recent earthquakes have plowed past previously inferred fault-rupture boundaries. That is, past models have generally assumed that earthquakes are either confined to separate faults, or that long faults like the San Andreas can be divided into different segments that only rupture separately. However, all three of the most-recent, largest earthquakes in California ruptured right past such boundaries, jumping from one fault to another as multifault ruptures. These were the 1992 magnitude 7.3 Landers, the 1999 magnitude 7.2 Hector Mine, and the 2010 magnitude 7.2 El Mayor-Cucapah earthquakes. The 2011 magnitude 9.0 Tohoku, Japan earthquake also violated previously defined fault-segment boundaries, resulting in a much larger fault-rupture area and magnitude than expected, and contributing to the deadly tsunami and Fukushima nuclear disaster.

Given these observations, the possibility of multifault ruptures clearly needed to be considered in our new model. In fact, as the inventory of California faults has grown over the years, it 
Readiness of Faults

(probability gain for $\mathrm{M} \geq 6.7$ earthquakes)

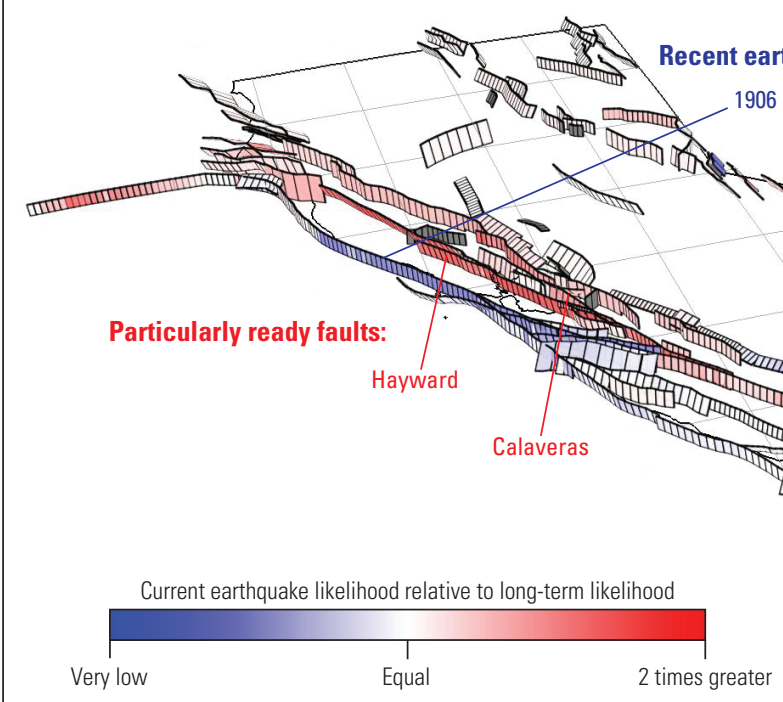

2 times greater
Figure 3. California earthquake likelihood in UCERF3 incorporates the concept that earthquake probabilities change with time according to elastic-rebound theory. Faults are less likely to rupture (less ready) when and where there has been a recent earthquake, and are more likely to rupture (more ready) where tectonic forces have built up during many years without an earthquake (although the event may still be several decades away) ( $\mathrm{M} \geq 6.7$, magnitude 6.7 or larger). 1983 Coalinga
Dancisco

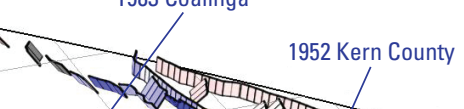
/

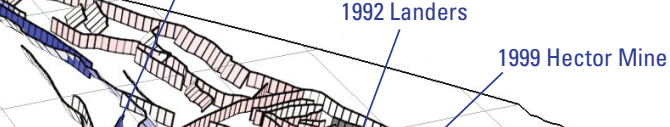

Southern San Andreas

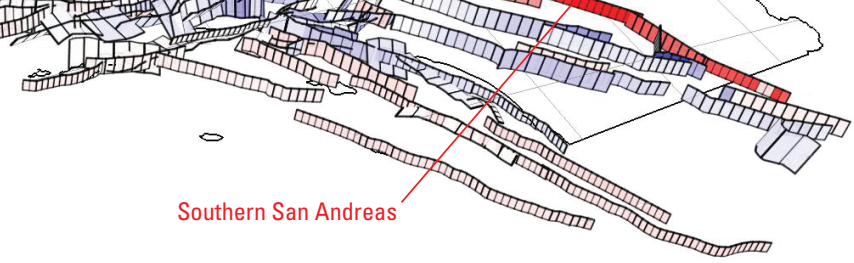

has become increasingly apparent that we are not dealing with a few well-separate faults, but with a vast interconnected fault system. In fact, it has become difficult to identify where some faults end and others begin, implying many more opportunities for multifault ruptures. As a consequence, UCERF3 now considers more than 250,000 different fault-based earthquakes, including multifault ruptures, whereas UCERF2 had about 10,000, and previous models had far fewer. Because we still lack a complete inventory of faults, UCERF3 (and UCERF2 before it) also includes the possibility of earthquakes on unrecognized faults elsewhere in the region.

Solving for the rate of all possible ruptures in the interconnected fault system represented a significant challenge. The UCERF3 methodological breakthrough, referred to as the "grand inversion," allowed us to not only solve for the rate of each earthquake rupture, but to also draw upon a broader range of observations in doing so. For example, the previous rate discrepancy at moderate-magnitudes was turned into part of the solution. That is, because the total plate-tectonic deformation is generally well known, any increase in the rate of larger, multifault ruptures must come with a consequent reduction in rates at lower magnitudes. The grand inversion manages the overall plate-tectonic, faultsystem budget mathematically, adding whatever multifault ruptures are needed to eliminate the rate discrepancy at moderate magnitudes. So, not only does UCERF3 include the types of multifault ruptures seen in nature, but doing so has also eliminated the overprediction of moderate-sized events, implying the latter was simply a manifestation of the isolation and segmentation of faults in the previous models.

UCERF3 also includes the notion of fault "readiness," where earthquake likelihoods go down on faults that have recently ruptured, and build back up with time as tectonic stresses reaccumulate. Although this concept, known formally as Reid's elastic rebound theory (Reid, 1911), has been around for more than a century, applying it in a model that includes multifault ruptures also proved challenging. A new methodology was therefore developed, which also relaxes the requirement that the date-of-last event be known where applied. That is, we may not know when the most recent event occurred on many California faults, but we do know that it had to have been prior to 1875 (the year when reliable recordkeeping began). Being able to account for this "historic open interval" for events that precede 1875 allowed us to quantify fault readiness throughout the entire fault system (fig. 3), rather than being limited to only a subset of faults as in previous studies.

There are many uncertainties in both the data and scientific theories that go into UCERF3, and alternative values for each element can lead to a different forecast. Consequently, UCERF3 is not a single model, but rather a collection of 5,760 different viable models. The results presented in the next section represent an average of these forecasts. Calculating grand-inversion results for all the models required the use of super computers, as they would have taken more than 8 years on a single desktop computer.

\section{What Are the Results, and How Do They Differ from Previous Estimates?}

UCERF3 results for various regions and faults of interest are shown in the figures and tables here. How have expected earthquake rates changed from the previous model? Overall, the results confirm earlier findings (California is earthquake country), but with some important refinements in certain areas. Considering the entire region, the average time between magnitude 6.7 and larger earthquakes has gone from 1 every 4.8 years in UCERF2, to 1 about every 6.3 years in UCERF3, representing a 30 percent decrease in the new forecasted 
Table 1. Average time between earthquakes in the various regions together with the likelihood of having one or more such earthquakes in the next 30 years (starting from 2014). Values listed in parentheses indicate the factor by which the rates and likelihoods have increased, or decreased, since the previous model (UCERF2). "Readiness" indicates the factor by which likelihoods are currently elevated, or lower, because of the length of time since the most recent large earthquakes (see text). These values include aftershocks. It is important to note that actual repeat times will exhibit a high degree of variability, and will almost never exactly equal the average listed here.

\begin{tabular}{|c|ccccc|c|}
\hline \multicolumn{8}{|c|}{ Greater California region } \\
\hline $\begin{array}{c}\text { Magnitude } \\
\text { (greater than } \\
\text { or equal to) }\end{array}$ & $\begin{array}{c}\text { Average } \\
\text { repeat time } \\
\text { (years) }\end{array}$ & $\begin{array}{c}\text { 30-year } \\
\text { likelihood of } \\
\text { one or more } \\
\text { events }\end{array}$ & $\vdots$ & $\vdots$ \\
\hline 5 & 0.12 & $(0.7)$ & $100 \%$ & $(1.0)$ & 1.0 \\
6 & 1.2 & $(0.9)$ & $100 \%$ & $(1.0)$ & 1.0 \\
6.7 & 6.3 & $(1.3)$ & $>99 \%$ & $(1.0)$ & 1.0 \\
7 & 13 & $(1.3)$ & $93 \%$ & $(1.0)$ & 1.0 \\
7.5 & 52 & $(1.0)$ & $48 \%$ & $(1.0)$ & 1.1 \\
8 & 494 & $(0.8)$ & $7 \%$ & $(1.5)$ & 1.2 \\
\hline
\end{tabular}

\begin{tabular}{|c|cccccc|}
\hline \multicolumn{7}{|c|}{ Southern California region } \\
\hline $\begin{array}{c}\text { Magnitude } \\
\text { (greater than } \\
\text { or equal to) }\end{array}$ & $\begin{array}{c}\text { Average } \\
\text { repeat time } \\
\text { (years) }\end{array}$ & $\begin{array}{c}\text { 30-year } \\
\text { likelihood of } \\
\text { one or more } \\
\text { events }\end{array}$ & $\vdots$ & \\
\hline 5 & 0.24 & $(0.7)$ & $100 \%$ & $(1.0)$ & 1.0 \\
\hline 6 & 2.3 & $(0.9)$ & $100 \%$ & $(1.0)$ & 1.0 \\
6.7 & 12 & $(1.5)$ & $93 \%$ & $(1.0)$ & 1.0 \\
7 & 25 & $(1.4)$ & $75 \%$ & $(0.9)$ & 1.1 \\
7.5 & 87 & $(1.2)$ & $36 \%$ & $(0.9)$ & 1.2 \\
8 & 522 & $(0.4)$ & $7 \%$ & $(2.5)$ & 1.3 \\
\hline
\end{tabular}

\begin{tabular}{|c|c|c|c|c|c|}
\hline \multicolumn{6}{|c|}{ Northern California region } \\
\hline $\begin{array}{l}\text { Magnitude } \\
\text { (greater than } \\
\text { or equal to) }\end{array}$ & $\begin{array}{r}\text { Av } \\
\text { repe } \\
\text { (y }\end{array}$ & $\begin{array}{l}\text { ge } \\
\text { time } \\
\text { s) }\end{array}$ & $\begin{array}{r}30- \\
\text { likeli } \\
\text { one o } \\
\text { ev }\end{array}$ & $\begin{array}{l}\text { od of } \\
\text { od ore } \\
\text { more } \\
\text { its }\end{array}$ & Readiness \\
\hline 5 & 0.24 & $(0.7)$ & $100 \%$ & (1.0) & 1.0 \\
\hline 6 & 2.4 & (0.9) & $100 \%$ & (1.0) & 1.0 \\
\hline 6.7 & 12 & (1.2) & $95 \%$ & (1.0) & 1.0 \\
\hline 7 & 25 & (1.2) & $76 \%$ & (1.0) & 1.1 \\
\hline 7.5 & 92 & (0.9) & $28 \%$ & (1.1) & 1.0 \\
\hline 8 & 645 & (0.8) & $5 \%$ & (1.4) & 1.1 \\
\hline
\end{tabular}

\begin{tabular}{|c|c|c|c|c|c|}
\hline \multicolumn{6}{|c|}{ San Francisco region } \\
\hline \multirow{2}{*}{$\begin{array}{c}\text { Magnitude } \\
\text { (greater than } \\
\text { or equal to) }\end{array}$} & \multicolumn{2}{|c|}{$\begin{array}{c}\text { Average } \\
\text { repeat time } \\
\text { (years) }\end{array}$} & \multicolumn{2}{|c|}{$\begin{array}{c}\text { 30-year } \\
\text { likelihood of } \\
\text { one or more } \\
\text { events }\end{array}$} & \multirow{2}{*}{$\begin{array}{c}\text { Readiness } \\
1.0\end{array}$} \\
\hline & 1.3 & $(0.7)$ & $100 \%$ & $(1.0)$ & \\
\hline 6 & 8.9 & (1.0) & $98 \%$ & $(1.0$ & 1.0 \\
\hline 6.7 & 29 & (1.1) & $72 \%$ & (1.1) & 1.1 \\
\hline 7 & 48 & (0.9) & $51 \%$ & (1.3) & 1.1 \\
\hline 7.5 & 124 & $(0.7)$ & $20 \%$ & (1.6) & 0.9 \\
\hline 8 & 825 & $(0.7)$ & $4 \%$ & (1.9) & 1.0 \\
\hline
\end{tabular}

\begin{tabular}{|c|ccccc|c|}
\hline \multicolumn{8}{|c|}{ Los Angeles region } \\
\hline $\begin{array}{c}\text { Magnitude } \\
\text { (greater than } \\
\text { or equal to) }\end{array}$ & $\begin{array}{c}\text { Average } \\
\text { repeat time } \\
\text { (years) }\end{array}$ & $\begin{array}{c}\text { 30-year } \\
\text { likelihood of } \\
\text { one or more } \\
\text { events }\end{array}$ & $\vdots$ & $\vdots$ & \\
\hline 5 & 1.4 & $(0.6)$ & $100 \%$ & $(1.0)$ & 1.0 \\
6 & 10 & $(1.1)$ & $96 \%$ & $(1.0)$ & 1.0 \\
6.7 & 40 & $(2.1)$ & $60 \%$ & $(0.8)$ & 1.1 \\
7 & 61 & $(2.0)$ & $46 \%$ & $(0.7)$ & 1.2 \\
7.5 & 109 & $(1.3)$ & $31 \%$ & $(0.9)$ & 1.3 \\
8 & 532 & $(0.4)$ & $7 \%$ & $(2.5)$ & 1.3 \\
\hline
\end{tabular}

rate (and note that most of these events occur in remote areas of the state). For magnitude 8 and larger, on the other hand, the rate has increased by 20 percent in UCERF3, with an expected repeat time of 494 years for UCERF3, down from 1 every 617 years in UCERF2. These changes are a direct and expected manifestation of including multifault ruptures in UCERF3. A more careful analysis of historical seismicity has also produced an increased rate for magnitude 5 and greater earthquakes, going from about 5.8 per year in UCERF2 to 8.3 per year in UCERF3. All of these trends are similar to those seen in various subregions of the state, with differences being slightly more dramatic for the Los Angeles area because that region has a large number of faults that can now host multifault ruptures.

Results are also expressed in terms of the likelihood of experiencing one or more earthquakes in the next 30 years, the duration of a typical home mortgage, and these values also take fault readiness into consideration (how long it has been since the most recent event). As in UCERF2, the likelihood for magnitude 6.7 and larger earthquakes somewhere in the entire region remains near certainty (greater than 99 percent). The likelihood is 7 percent for magnitude 8 and greater, a 50 percent increase over UCERF2, resulting from both the inclusion of multifault ruptures and the particular readiness of some large faults.

One particularly ready fault is the Southern San Andreas, which contributes to its continued status of being the most likely to host a large earthquake. Specifically, it has a 19 percent chance of having one or more events larger than magnitude 6.7 in the next 30 years near Mojave, Calif. The comparably low values for the Northern San Andreas, such as 6.4 percent near San Francisco, are partly because of the relatively recent 1906 earthquake on that fault. In fact, probabilities on two other Bay Area faults, the Hayward-Rodgers Creek and the Calaveras, currently rival or exceed those on the Northern San Andreas, in part because they are both relatively ready.

Compared to the previous model, UCERF2, the San Jacinto fault has a three-fold decrease in the likelihood of magnitude 6.7 or larger earthquakes. Much of this decrease is because of the inclusion of more multifault ruptures, as indicated by the factor of 57 increase in the likelihood of magnitude 8 and larger earthquakes. In other words, the fault has traded some moderate-sized events for rare larger ones.
The Calveras fault, on the other hand, has a three-fold increase in the likelihood of magnitude 6.7 or larger earthquakes. In UCERF2 most Calaveras events were well below magnitude 6.7 , so the inclusion of multifault ruptures in UCERF3 has increased the frequency of earthquakes above magnitude 6.7.

We have only touched on a few of the more important changes between UCERF2 and UCERF3, and have highlighted only some of the influential factors. Many more are currently understood, and scientists will be further analyzing results and testing assumptions for years to come.

So what do these changes imply with respect to seismic hazard, the likelihood of ground shaking, as well as for seismic risk, the threat to the built environment with respect to fatalities and economic losses? The answer turns out to be entirely dependent on what you are concerned about. For example, increasing the likelihood of large multifault earthquakes, which consequently reduces the likelihood of moderate-sized events, may increase the risk to tall buildings or large bridges, but actually lower the risk to residential homes.

As a consequence, it is difficult to make generalizations about the hazard or risk implications of UCERF3 without first specifying both asset types and their locations. Conclusions will vary depending on whether you are designing a single family dwelling in Sacramento, retrofitting the San Francisco-Oakland Bay Bridge, considering the location of a nuclear power plant, laying pipeline across the San Andreas Fault, or considering aggregate losses over a large insurance portfolio. The practical implications will need to be considered on a case-by-case basis.

\section{What Next?}

UCERF3 can now be used to evaluate seismic hazard and risk in California. In fact, it has already been used for the 2014 update of the U.S. Geological Survey National Seismic Hazard Maps (http://earthquake.usgs.gov/hazards/), which in turn are used in building codes. The California Earthquake Authority, which is required by law to use the best available science, will use UCERF3 to evaluate insurance premiums charged to customers, as well as their own level of reinsurance. UCERF3 will be used in many other risk mitigation 
Tabulated values represent the likelihood of having one or more earthquakes in the next 30 years (starting from 2014).

[At the points on the fault indicated by white circles. $M \geq 6.7$ means magnitude greater than or equal to 6.7 , and likewise for the other two magnitude thresholds. \%, percent. Values listed in parentheses indicate the factor by which the likelihoods have increased, or decreased, relative to the previous model (UCERF2), where "--" means the previous value was zero. "Readiness" indicates the factor by which probabilities are currently elevated, or lower, because of the length of time since the previous large earthquake]

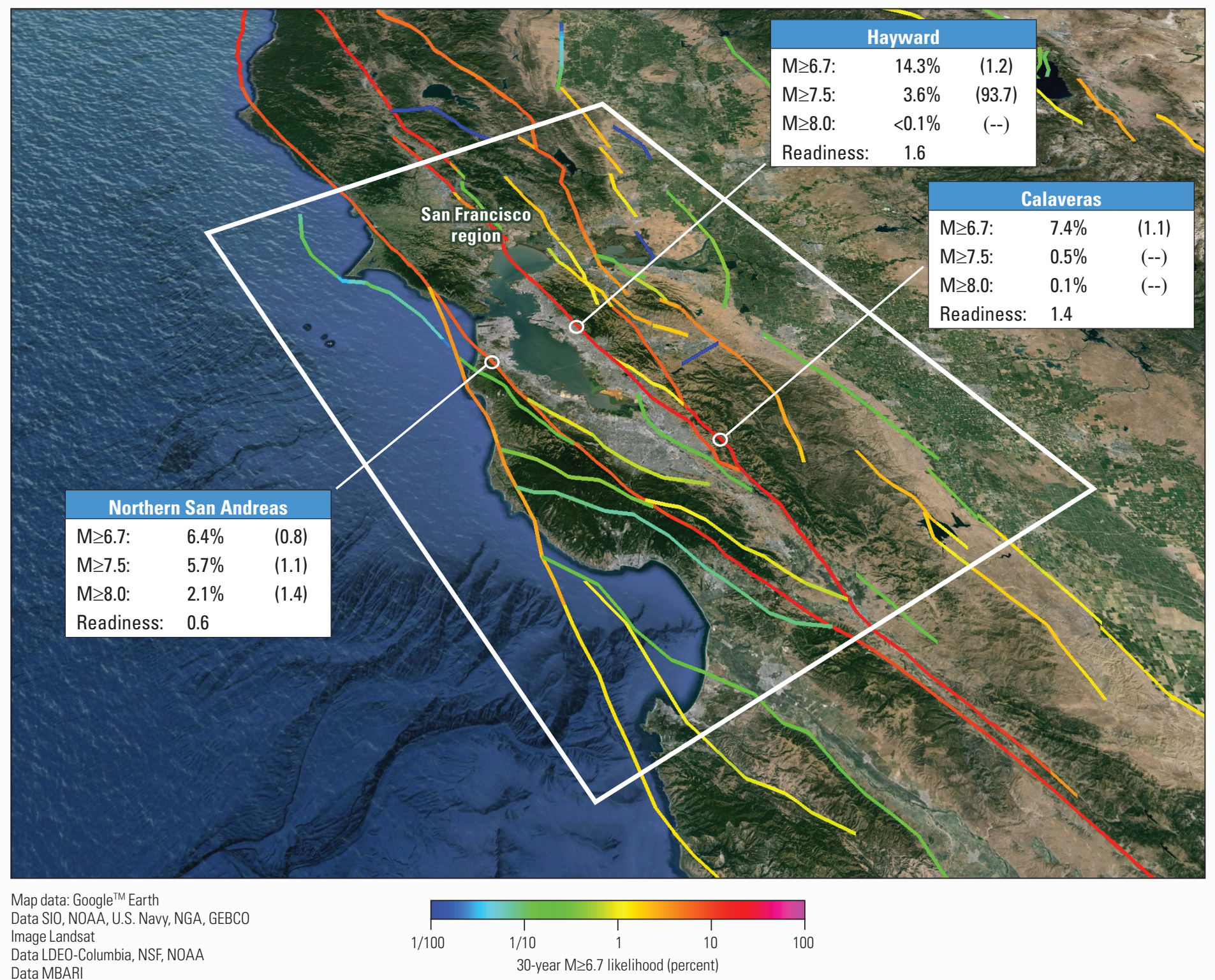

Figure 4. Likelihood of magnitude 6.7 or greater earthquakes in the next 30 years, from 2014, on the faults near San Francisco, Calif.

efforts in the years to come, including engineering design of buildings and lifelines, loss estimation for catastrophic bonds and other risk-linked securities, and emergency preparedness, all of which have the ultimate goal of increasing public safety and community resilience.

UCERF3 should also serve as a reminder that California is earthquake country, and residents should always be prepared. Simple safeguards include practicing "drop, cover, and hold on," securing items in your home and workplace that could fall during an earthquake, and storing sevendays worth of food and water. Homeowners can also consider structural retrofits, such as bolting the house to its foundation, as well as earthquake insurance options. For further guidance on how to prepare for, survive, and recover after big earthquakes, follow the Seven Steps to Earthquake Safety (http://www.earthquakecountry.org/ sevensteps).

Although UCERF3 is a clear improvement over the previous model (UCERF2), it is still an approximation of the natural system. For example, it does not model the earthquaketriggering process that produces aftershocks, even though we know such events can be large and damaging. Through the National Earthquake Hazard Reduction Program (http:// www.nehrp.gov), the U.S. Geological Survey and its partners will continue to conduct research aimed at improving our understanding of fault behavior and estimates of earthquake hazard in the future. 
Tabulated values represent the likelihood of having one or more earthquakes in the next 30 years (starting from 2014).

[At the points on the fault indicated by white circles. $M \geq 6.7$ means magnitude greater than or equal to 6.7 , and likewise for the other two magnitude thresholds. \%, percent. Values listed in parentheses indicate the factor by which the likelihoods have increased, or decreased, relative to the previous model (UCERF2), where "--" means the previous value was zero. "Readiness" indicates the factor by which probabilities are currently elevated, or lower, because of the length of time since the previous large earthquake]

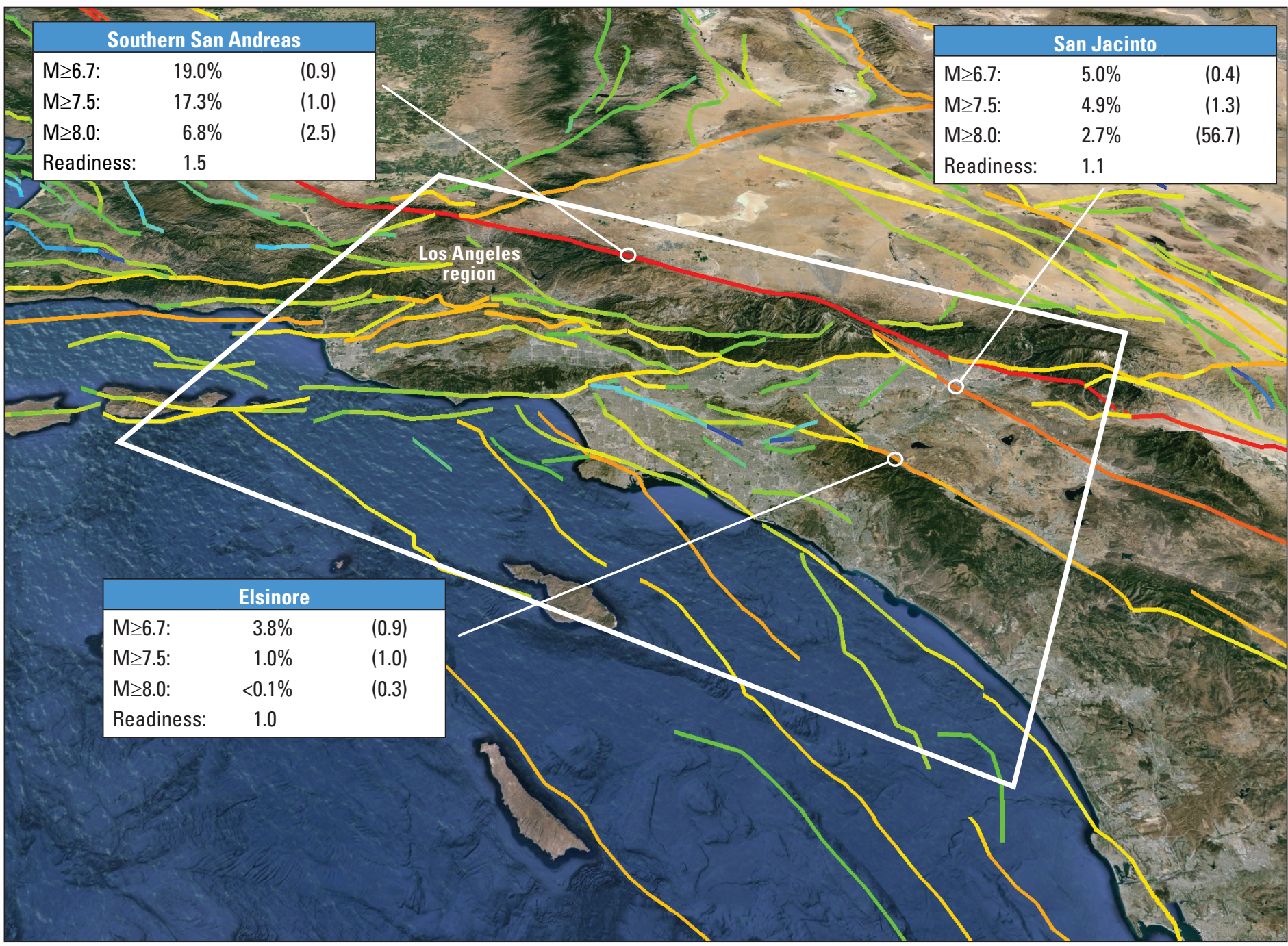

Map data: Google ${ }^{\mathrm{TM}}$ Earth

Data SIO, NOAA, U.S. Navy, NGA, GEBCO Image Landsat

Data LDEO-Columbia, NSF, NOAA

Data MBARI

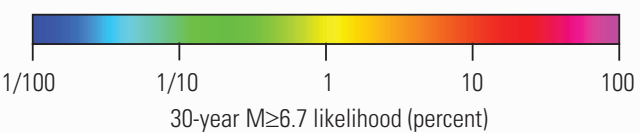

Figure 5. Likelihood of magnitude 6.7 or greater earthquakes in the next 30 years, from 2014, on the faults near Los Angeles, Calif.

\section{References}

Korzybski, A. 1931, A non-Aristotelian System and its necessity for rigour in mathematics and physics: presention at the American Mathematical Society, December 28, 1931, New Orleans, Louisiana, meeting of the American Association for the Advancement of Science. Reprinted in Science and Sanity, 1933, p. 747-61.

Reid, H.F., 1911, The elastic-rebound theory of earthquakes: University of California Publications, Bulletin of the Department of Geological Sciences v. 6, p. 413-444.

Working Group on California Earthquake Probabilities, 2007, Published as: Field, E.H., Dawson, T.E., Felzer, K.R., Frankel, A.D., Gupta, V., Jordan, T.H., Parsons, T., Petersen, M.D., Stein, R.S. Weldon, II, R.J., and Wills, C.J., 2009, Uniform California earthquake rupture forecast, Version 2 (UCERF 2): Bulletin of the Seismological Society of America, v. 99, p. 2053-2107, doi:10.1785/0120080049.
Working Group on California Earthquake Probabilities, in press, Published as: Field, E.H., Biasi, G.P., Bird, P., Dawson, T.E., Felzer, K.R. Jackson, D.D., Johnson, K.M., Jordan, T.H., Madden, C. Michael, A.J., Milner, K.R., Page, M.T., Parsons, T., Powers, P.M., Shaw, B.E., Thatcher, W.R., Weldon, R.J. II, , and Zeng, Y., 2015, Long-term, time-dependent probabilities for the third uniform California earthquake rupture forecast (UCERF3), Bulletin of the Seismological Society of America.

-Authors: Edward H. Field and members of the 2014 WGCEP

Cooperating organizations:

Southern California Earthquake Center (SCEC)

California Geological Survey (CGS)

California Earthquake Authority

U.S. Geological Survey

\section{Additional Resources:}

For general earthquake information contact: 1-888-ASK-USGS (1-888-275-8747)

http://earthquake.usgs.gov/

http://ask.usgs.gov

or

SCEC Education and Outreach: 213-740-3262

For UCERF3 information see:

http://www.WGCEP.org/UCERF3

For technical questions contact:

Edward (Ned) Field: field@usgs.gov 